\title{
NUEVOS HORIZONTES DE LOS DERECHOS HUMANOS: LA CRISIS DE LA MODERNIDAD JURÍDICA EN LA SOCIEDAD TECNOLÓGICA ${ }^{1}$
}

NOVOS HORIZONTES DOS DIREITOS HUMANOS: A CRISE DA MODERNIDADE JURÍDICA NA SOCIEDADE TECNOLÓGICA

\author{
Alfonso de Julios-Campuzano
}

\section{RESUMEN}

Pensar el derecho contemporaneo implica tenermos presentes los fenómenos que caracterizan a la nueva sociedad que se va formando con los procesos de transformación social y tecnológica, buscando las referencias para la construcción de un nuevo paradigma para los derechos humanos. Este es el objetivo de este trabajo.

Palabras clave: Derechos Humanos. Modernida. sociedad tecnológica.

\section{ABSTRACT}

Thinking about contemporary law implies that we present the phenomena that characterize the new society that is forming with the processes of social and technological transformation, seeking the references for the construction of a new paradigm for human rights. This is the purpose of this work.

Keywords: Humano Rights. Modenity. technological society. 


\section{LA GESTACIÓN DEL DERECHO DE LA MODERNIDAD}

La gestación del sistema jurídico de la modernidad es un proceso lento que se va desarrollando de forma paulatina a lo largo de varios siglos. En él inciden muchos factores que irán, con el discurrir del tiempo, conformando los perfiles del fenómeno jurídico en la modernidad. A partir de la concentración del poder en las monarquías centralistas europeas, de la Revolución Industrial, de la irrupción de la burguesía como clase política dominante y bajo la égida racionalizadora del pensamiento ilustrado, el derecho tiende a adquirir características distintivas que vendrán a consolidar una nueva concepción de lo jurídico más acorde con el nuevo orden social, político y económico. Resulta evidente que el nuevo orden precisaba de categorías jurídicas accionables que concretaran los ámbitos de poder -obligaciones y derechos- en la sociedad, y que esas categorías jurídicas, lejos de ser principios abstractos, universales y absolutos, desposeídos de corporeidad histórica, obedecían a concretas circunstancias que determinaron su propia identidad como pilares del nuevo orden jurídico.

Con anterioridad a este proceso, el arrinconamiento del iusnaturalismo por la irrupción del paradigma cientificista del derecho constituyó un hito decisivo en la configuración de ese nuevo orden jurídico. Desprovisto de exigencias axiológicas materiales, el derecho quedó reducido a una cuestión de poder, y el establecimiento de las normas jurídicas concretas, a un reparto del poder social entre aquellos que podían acceder a él. El igualitarismo jurídico quedó plasmado en el reconocimiento puramente formal de la igualdad de todos los ciudadanos ante la ley, con lo que este principio quedaba comprometido con la preservación de un orden social y económico que se asentaba sobre el reconocimiento explícito de la desigualdad entre las clases sociales ${ }^{2}$. Y todo ello, desde la exaltación de un conocimiento objetivo, aséptico y neutral ${ }^{3}$ del derecho, que en absoluto era nada de lo que proclamaba y que resultaba ser ideológico y comprometido con la preservación de un determinado statu quo, como acertadamente denuncia Marí: "La confianza que se deposita ahora en los códigos radica en su posibilidad de actuar como mecanismos de libertad y expansión de los mercados, mecanismos de anulación de los tabús sacramentales y las asociaciones estamentarias o gremiales monopólicas de orden cerrado, 
mecanismos, en fin, de embarazo y trabas a la reproducción de abusos con resonancias del imperium.

Todo el honor del programa de la nueva codificación se instala en esta línea: lograr pory en las leyes sistematizadas, obtener por y en los códigos, el mayor incremento posible de consensualidad, de libre contratación, y de penalidades y convenios racionales.

Esta línea está conformada por un solo tejido: la Razón. Razón en reemplazo de la autoridad divina que era el referente de legitimación del poder según la concepción descendente (el poder desciende de lo alto a lo bajo), que circuló desde el imperio carolingio hasta la edad moderna.

Razón cartesiana, absoluta, que atraviesa la historia sin que la embarace ningún relativismo. Por el contrario, ella es constitutiva, la que pone las condiciones del pensamiento y la historia. Facultad del hombre, erigida ahora en fuente inmanente y no trascendente de legitimación del poder. Razón continua y evolutiva en la que se inscribirá la idea iluminista del progreso indefinido propia de los enciclopedistas y los hombres del Aufklärung, y razón a la que deberán ajustarse los derechos positivos, legislados, si quieren merecer el carácter de tales, o sea condición de validez . Para este iusnaturalismo racionalista, en efecto, el derecho es un producto de la razón constante ahistórica, porque atraviesa todas las historias. Patrimonio de bases universales (todos los hombres son iguales ante la ley) y racionales"4.

\section{CODIFICACIÓN, ORDENAMIENTO JURÍDICO Y MODERNIDAD}

Este proceso, sin embargo, supuso una ruptura importante con respecto a las aportaciones del pensamiento ilustrado, cuyos antecedentes iusnaturalistas habían conformado los perfiles de las categorías básicas del nuevo sistema jurídico, que ahora, por obra del cientificismo positivista, han quedado desprovistas de su originaria matriz histórica. El advenimiento del positivismo marca así un punto de inflexión en la evolución de los principios y doctrinas jurídicas y en la propia conformación de los modelos jurídicos nacionales. A partir de 
ahí, las garantías jurídicas fundamentales de la tradición democrática occidental son desprovistas de su referente axiológico para constituirse en fines en sí mismas, apoyando con ello el surgimiento de un conjunto de ficciones que darán soporte a la conformación de un sistema jurídico basado en el reconocimiento puramente formal de principios y garantías. De este modo, la radicalización de algunos de los elementos teóricos del iusnaturalismo racionalista -presentes, como ya hemos visto, en las formulaciones de Pufendorf y Leibniz, entre otros- sienta las bases para su sustitución por el paradigma positivista que, de manera poco sutil, procederá a invertir sus postulados teóricos, prescindiendo de la matriz axiológica que le confería su soporte. Los derechos subjetivos, convertidos en categorías estrictamente formales y jurídico-positivas, vienen así a suplantar a los primitivos derechos humanos de marcada resonancia iusnaturalista y, con ello, quedan anclados en la voluntad del legislador y en los límites estrictos de una normatividad positiva ajena a las circunstancias personales de los sujetos titulares de los derechos. Queda así establecido el vínculo entre los derechos fundamentales y los derechos públicos subjetivos, obra de la ciencia alemana del derecho público que, bajo los auspicios del positivismo, vendrá a subvertir definitivamente la fuerza emancipatoria, liberadora y revolucionaria de los derechos humanos, convertidos ahora ya en una coartada teórica para la preservación del statu quo y la consagración del dominio social, político, económico y jurídico de la burguesía. Esta entronización del formalismo jurídico desde los presupuestos del positivismo que cosifica los derechos reduciéndolos a categorías formales se gesta, como significativamente ha hecho notar Ferrajoli, a partir de la contribución de Gerber, primero, al reducir los derechos públicos a una serie de efectos del derecho público radicados más en la existencia abstracta de la ley que en la esfera pública del individuo, destacándose su configuración como elementos orgánicos distintivos de un Estado concreto. A partir de esta aportación, la dogmática iuspublicista de finales del XIX, desde Laband a Jellinek, de Santi Romano a Vittorio Emmanuele Orlando, consagrará definitivamente los derechos fundamentales como derechos públicos subjetivos, expresión normativa de una voluntad que se autolimita, prescindiendo del referente axiológico que constituía su soporte y 
fundamento en la tradición iusnaturalista racionalista. Esa formulación no sólo entra en contradicción con el paradigma iusnaturalista de los derechos fundamentales sino también con el paradigma constitucional que al positivar tales derechos los configuró como vínculos y límites frente a los poderes públicos y fundamento de su legitimidad ${ }^{5}$.

La modernidad no se desenvuelve en una única dirección ni puede decirse que constituya un proyecto unidireccional. Y es esta ruptura que el positivismo inaugura con el pensamiento ilustrado anterior -el iusnaturalismo racionalista-, la que marca el inicio de un segundo momento en la gestación del nuevo orden jurídico que prevalece hasta nuestros días. De este modo, la razón metafísica se torna razón matemática, científica, con la llegada del positivismo, con lo que se produce un vaciamiento de las exigencias axiológicas materiales que establecía el iusnaturalismo racionalista ${ }^{6}$. De su mano queda definitivamente configurada la concepción del derecho como sistema, que recibiría su definitiva formulación como ordenamiento jurídico con la publicación de la obra L'ordinamento giuridico, de Santi Romano. Y esa ordenación sistemática de lo jurídico, estatal y positivo como el único derecho posible, recaba para sí los principios de plenitud y coherencia, de modo que sus partes integran un todo sin contradicciones internas y capacidad de respuesta ante todos los problemas que precisen una solución normativa, tanto presentes como futuros. El código como bálsamo reparador que todo lo cura. Más allá de él no hay derecho, más allá del derecho sólo hay caos. Es así como el positivismo completa el paroxismo de la abstracta razón ilustrada, despojada, ahora ya, de su impronta iusnaturalista: si la razón todo lo puede, sus principios serán universales, válidos en cualquier circunstancia y lugar. Si el derecho es racional, entonces ¿qué hay que temer? Consagremos el reino del derecho -y la justicia-, olvidándonos de las exigencias axiológicas que deben inspirarlos. Y asegurémonos de que sus normas serán siempre cumplidas, incluso en caso de ignorancia. Poco importa que quienes sufran el rigor de este legalismo extremo puedan o no conocer efectivamente el derecho vigente. Demos, pues, apariencia de racional al derecho, porque así podrá sentirse como racional nuestra dominación. 
Con esta forma de entender el derecho y la ordenación social, propios del capitalismo decimonónico y de la ciencia del derecho que daba soporte jurídico al Estado de Derecho liberal-burgués, se daba un paso decisivo en un proceso de inversión de los postulados teóricos del proyecto ilustrado a partir de algunas de sus propias premisas que, radicalizadas, sirvieron para proclamar el dominio absoluto de la razón abstracta y universal, prescindiendo de exigencias y referentes axiológicos materiales, cuyo valor normativo quedaba desterrado del ámbito de lo jurídico. Los desarrollos del proyecto de la modernidad han quedado, pues, determinados por lecturas sesgadas de su alcance emancipatorio; algunas de ellas han servido de fundamento teórico a prácticas históricas de dominación social y política que tuvieron una plasmación en los modos de organización económica del capitalismo indiscriminado del laissez faire. Esta perversión ideológica se sustentó sobre el corolario político de la democracia puramente formal y el sistema jurídico pretendidamente aséptico y neutral que establecía, a partir del reconocimiento formal de derechos para todos y el reparto de poder en el ámbito del goce efectivo de esos mismos derechos; en última instancia, la iniquidad del sistema quedaba amparada por un uso perverso de la seguridad jurídica, como garantía de la aplicación indiscriminada del derecho positivo.

Surge así un modelo de jurista impregnado de la "voluntad de la ley" -como si la ley fuese realmente un ser con capacidad volitiva- que no se cuestiona la bondad de instituciones y normas, que se limita a aplicar el Derecho (dura lex, sed lex; Gesetz ist Gesetz) sin advertir que su responsabilidad ante la sociedad requiere un compromiso decidido con los valores; un jurista técnico que rehúye los análisis interdisciplinares y que no admite más exégesis que la del texto legal cuando los términos del mismo no resultan suficientemente claros (in claris non fit interpretatio).

Se realza, por tanto, la dimensión técnica en detrimento de la humanística, a partir de una comprensión profundamente sesgada del Derecho como producto químicamente puro: un Derecho que se limita a operar al margen de la realidad social mediante mecanismos lógicos falsamente asépticos, que se construye desde la negación de la sociedad como categoría de análisis de lo jurídico y que omite que la neutralidad encubre un nada despreciable valor ideológico. 
¿Qué se puede decir de esa reducción de la multiplicidad a la unidad? ¿También es algo realizado desde los presupuestos pretendidamente científicos de una lógica puramente formal? ¿0 acaso estamos, ni más ni menos, que ante la articulación de opciones previas sobre valores que constituirán las premisas ocultas de las que se habrá de partir en la aplicación lógica de las normas? ¿No estamos, en definitiva, encubriendo bajo la apariencia de una cientificidad meramente figurada la realidad incuestionable de que el Derecho es, prioritariamente, una opción por la realización de determinados valores? Digámoslo de una vez por todas. Confesemos con rotundidad frente a los diestros y crédulos peritos en un Derecho falsamente esterilizado que tras toda operación lógica subyace una opción previa y que todo análisis de lo jurídico que omita esta realidad está reduciendo el Derecho a uno de sus aspectos, el menos importante quizá, quién sabe si con la ominosa pretensión de ideologizar y mitificar las categorías jurídicas sobre las que ese modelo descansa. Por eso, carece de sentido seguir sosteniendo en nuestros días la idea de un Derecho químicamente puro, un producto de laboratorio elaborado sin tener en cuenta los condicionantes sociales, económicos, políticos y éticos, al margen del conjunto de las realidades humanas y distante del ser humano que es su actor a la vez que su destinatario. Y es que, como afirma Ollero, el Derecho no se ofrece como una realidad acababa, cerrada, conclusa de una vez para siempre, sino que es objeto de una participación en su propio proceso de conocimiento: el jurista, cuando conoce, está haciendo suya la norma, de modo que el objeto de conocimiento deja de ser algo objetivo y ajeno a la propia realidad del jurista que lo interpreta y lo conoce, en la medida en que, conociéndolo, inevitablemente, lo transforma ${ }^{7}$. Y esta operación de mera aplicación de la norma no es en absoluto neutral ni aséptica, pues al tomar decisiones sobre la individualización y concreción de las normas abstractas elaboradas por el legislador los juristas intervienen, consciente o inconscientemente, como agentes del poder político ${ }^{8}$.

Por eso, como recuerda Barcellona, es necesario que el jurista salga del "círculo mágico de sus fórmulas abstractas, del cerrado horizonte de las normas" y que afronte directamente el problema de los contenidos materiales de la justicia 9 . 
Desde ya, el jurista tiene que ser consciente de que el Derecho precisa un grado más de razón para deshacer la hiperracionalidad de un cientificismo sin pálpito. Desde ahora hay que deshacerse del velo: la realidad exige que la contemplemos de frente. Hay que aprender a incorporar nuevas dimensiones de análisis a lo jurídico: porque el Derecho por sí no se comprende, necesita de la ayuda de otras ciencias, precisa del apoyo de un aparato crítico que le haga contrastar las categorías de laboratorio de una dogmática longeva y caduca. Es necesario superar, como ya dije en otro lugar, la impronta formalista de un sistema jurídico que se erige en sistema independiente, aislado del resto de los fenómenos sociales.

Es preciso remover los cimientos de un paradigma anacrónico y fosilizado de comprensión del Derecho y para ello se hace imprescindible superar la pesada carga de dogmas y mistificaciones, de conceptos y categorías huecas que nada pueden aportar ya al Derecho que está por venir. En nuestros días, por ejemplo, no parece que pueda seguir sosteniéndose el predominio de la autonomía de la voluntad en el ámbito de las relaciones entre particulares que ignora, como ya se ha apuntado, la flagrante asimetría de la mayoría de las operaciones mercantiles. Esa dimensión crítica hacia el propio Derecho importa no sólo en cuanto al cuestionamiento de las viejas categorías y conceptos de la dogmática tradicional, sino también en lo que atañe a una labor de construcción de un saber jurídico adecuado a las nuevas circunstancias de un mundo que dejó de ser el que era. ¿Acaso no están ya maduras las circunstancias -se pregunta Eriksson- como para crear nuevos conceptos básicos (y no solamente nuevos principios) en el derecho moderno, conceptos que tengan en cuenta la fragmentación de nuestras sociedades y la naturaleza conflictiva del derecho moderno ${ }^{10}$.

De este modo, se traba en los orígenes de la modernidad, como apunta Carrino, una estrecha relación entre saber y voluntad de poder, a lo cual contribuye de forma decisiva el positivismo jurídico, contribuyendo al debilitamiento de los viejos órdenes cognoscitivos por parte de la ciencia, individualizando en el ordenamiento sistemático de las leyes positivas la forma de manifestación del derecho objetivo. Para ello, el positivismo sentó las bases para una separación neta entre la abstracta "persona jurídica" y el individuo concreto, determinado. 
A partir de ahora, la libertad en términos jurídicos queda abstraída de toda actividad humana concreta. El positivismo, al contraponer a la personalidad concreta una humanidad abstracta, realiza la tendencia de la modernidad a la homogeneización, a la indiferencia, al dominio de lo abstracto sobre lo concreto, manifestándose así como un proceso de totalización, de modo que a partir del individualismo se llega a lo que Piovani denomina "totalismo", a la alienación de los individuos por la Subjetividad que les trasciende ${ }^{11}$.

Pero, a pesar de este lastre, hemos de reconocer que el proyecto de la modernidad no fue completamente malogrado, aunque no faltaron precisamente quienes aprovecharon sus elementos teóricos para invertir sus principios y postulados. Frente a la vorágine devoradora del capitalismo desenfrenado y a la instrumentalización teórica del pensamiento ilustrado, prevalecieron importantes innovaciones que fueron felizmente conquistadas para toda la humanidad. El fenómeno jurídico como manifestación de una voluntad política soberana concretada en procedimientos democráticos, la racionalización del derecho a través de los principios de publicidad, de seguridad jurídica o de jerarquía normativa y el imperio de la ley como garantía de la interdicción de la arbitrariedad de los poderes públicos, entre otras, fueron conquistas que afianzaron también el camino de igualdad y libertad que el proyecto de la modernidad prometía para todos. Y en esa amalgama en que teoría y práctica quedaron fundidas, prevaleció también la conquista mayúscula de la modernidad, sesgada, como ya se ha apuntado, por la limitación fáctica de la desigualdad material en el goce de los derechos: los derechos humanos como referente moral de una sociedad democrática y comprometida con los valores del individuo, con su autonomía y su dignidad.

\section{PRODUCCIÓN NORMATIVA Y SEGURIDAD JURÍDICA EN UN CONTEXTO GLOBAL}

Las nuevas formas del capitalismo maduro, aceleradas en las coordenadas de la globalización, y la creciente complejidad de los 
procesos sociales y políticos, unidas a los avances científicos, la revolución informática y la propia insuficiencia de la estructura estatal ante procesos de integración que se anuncian irreversibles, entre otros factores reseñables, han contribuido a crear un ambiente de crisis en torno al proyecto de la modernidad y al sistema jurídico abstracto y universal sobre el que éste se asentó; crisis que es preconizada desde distintos sectores del pensamiento y que, abundando en las raíces teóricas de la modernidad, insisten en poner de relieve la insuficiencia, cuando no directamente la inviabilidad, del proyecto moderno y del sistema jurídico que éste vino a propiciar. Esta conciencia de crisis se ha visto particularmente favorecida por el desbordamiento de los modelos tradicionales ante los vertiginosos avances tecnológicos y las mutaciones que éstos han provocado en la dinámica económica, social y política de un mundo cada vez más interdependiente. Todos estos cambios sociales apuntan hacia un cambio de paradigma cultural, cuya irreversibilidad sería consecuencia de la constante mutación de la organización social, como consecuencia de la irrupción de las nuevas tecnologías. Entre los rasgos fundamentales de esa situación de crisis, Faria advierte el surgimiento de nuevas fuentes de producción jurídica que apunta a la multiplicación de actores jurídicos en el escenario supra e infraestatal, el policentrismo decisorio que contrarresta la concentración de poder en los Estados y debilita crecientemente su poder y capacidad, la tendencia a la desregulación, a la deslegalización y a la contractualización del fenómenos sociales, que se traduce en una retirada de la normatividad jurídica y en una mutación profunda de su funciones y alcance y la aparición de una nueva estructura de la normatividad jurídica de carácter eminentemente reticular, con un retroceso significativo de los principios de unidad, racionalidad y estatalidad, lo cual suscita la necesidad de pensar el derecho desde nuevos paradigmas ajenos al formalismo de épocas pretéritas ${ }^{12}$. En ese contexto, se producen significativas transformaciones en el ordenamiento jurídico, en la estructura de la producción normativa, en el sistema de los derechos fundamentales y en el armazón conceptual que lo sostiene y le da soporte, propiciando un giro desde la unidad al pluralismo, de la plenitud a la apertura jurisdiccional y de la coherencia 
a la argumentación que conducen a una concepción policéntrica del ordenamiento y hacen sucumbir definitivamente el horizonte explicativo del positivismo jurídico, como certeramente ha apuntado el profesor Pérez Luño ${ }^{13}$.

El fenómeno de la globalización constituye, sin duda alguna, una de las claves explicativas de nuestro tiempo, cuya capacidad transformadora está transmutando drásticamente los procesos socioeconómicos, forzando simultáneamente un repertorio más amplio de cambios complejos que alcanzan a los diferentes ámbitos de la vida social, desde la política a la cultura, desde las relaciones humanas hasta el derecho. Por globalización nos referimos, pues, a un conjunto poliédrico y a menudo contradictorio de procesos económicos, políticos, sociales y culturales que son característicos de nuestra era. En términos económicos, las figuras más relevantes de la globalización, liderada por firmas multinacionales, son el desarrollo de redes de producción internacionales, la dispersión de las plantas de producción entre diferentes países, la fragmentación técnica y funcional de la producción, la fragmentación de la propiedad, la flexibilidad de los procesos productivos, el abastecimiento mundial, la interpenetración de los mercados financieros internacionales, los flujos transnacionales de información, los cambios en la naturaleza del empleo y el surgimiento de nuevas formas de trabajo. Desde este punto de vista la globalización ha supuesto la aparición de nuevos actores, tales como las organizaciones no gubernamentales, las corporaciones transnacionales y los movimientos sociales y ha tendido a debilitar, fragmentar e incluso reestructurar el Estado ${ }^{14}$.

La globalización representa, como sostiene Octavio Ianni, un nuevo ciclo de expansión del capitalismo, como modo de producción y proceso civilizatorio de alcance mundial ${ }^{15}$; un ciclo caracterizado por la integración de los mercados de forma avasalladora y por la intensificación de la circulación de bienes, servicios, tecnologías, capitales e informaciones a nivel planetario. De este modo, la globalización aparece concebida como la "integración sistémica de la economía a nivel supranacional, deflagrada por la creciente diferenciación estructural y funcional de los sistemas productivos y por la subsiguiente ampliación de las redes empresariales, comerciales y financieras a escala mundial, actuando de modo cada vez 
más independiente de los controles políticos y jurídicos a nivel nacional”16. Es lo que Wallerstein ha denominado "economía mundial capitalista": un nuevo marco económico mundial regido por el sistema capitalista cuya dinámica expansiva alcanza así su culminación. De un extremo a otro del planeta, el capitalismo se extiende y se ramifica en múltiples derivaciones locales, un único sistema cuyos desdoblamientos crean una imagen de particularidad. La economía mundial capitalista aparece, entonces, como un marco de referencia regido por tres elementos básicos: el principio de maximización de los beneficios, la existencia de estructuras estatales que intervienen en los procesos económicos, en aras de la máxima productividad de determinados grupos, y la estratificación del espacio internacional, en virtud de las condiciones de explotación que imperan en las relaciones entre Estados como consecuencia de un orden económico internacional inicuo ${ }^{17}$.

Estas alteraciones de la economía provocan un conjunto concatenado de reacciones que van desde la disminución de la capacidad de reglamentación de los gobiernos a la aparición de nuevas configuraciones geopolíticas con poder para controlar los flujos productivos, mercantiles, monetarios y migratorios ${ }^{18}$. La globalización genera una multiplicidad de conexiones y relaciones entre Estados y sociedades, multiplicidad que trastoca y que quiebra los esquemas de un orden socio-político basado en la diferenciación a través de las estructuras propias de los mercados nacionales. La globalización es algo más que un proceso de superación de las economías parciales de los Estados y su suplantación acelerada por un único espacio de intercambio de carácter global. Implica, fundamentalmente, un salto cualitativo en la expansión del capitalismo, un capitalismo que, al desvincularse del modelo económico estatal, se convierte en apátrida, un capitalismo sin raíces y sin territorio, que va de acá para allá buscando el máximo beneficio en un escenario de soft law y de desregulación que alcanza al reconocimiento, garantía y efectividad de los derechos humanos ${ }^{19}$. La interconexión, propiciada por las comunicaciones y por las nuevas tecnologías, ha provocado la reducción espacial del mundo, cuyos confines resultan ahora fácilmente abarcables ${ }^{20}$. No hay camino inexplorado ni tierra ignota: lo desconocido ya no existe. Evocando la tesis de Fukuyama sobre el fin de la historia, 
Richard 0'Brien ha proclamado el "fin de la geografía": las distancias ya no importan y la idea de frontera geográfica es cada vez más insostenible en el mundo real. En efecto, la distancia no es un dato objetivo, sino que es, ante todo, un producto social, una magnitud relativa asociada a la capacidad humana para salvarla ${ }^{21}$. En nuestro tiempo no hay nada demasiado lejano e inaccesible.

En este sentido, nuestra era viene marcada por dos fenómenos fundamentales: la reducción del espacio geográfico y la creación del espacio cibernético. Una red de comunicaciones abraza el planeta de un extremo a otro: carreteras, rutas marítimas y aéreas, satélites, fibra óptica, ondas electromagnéticas... Un manto tupido y enmarañado de comunicaciones que elimina los obstáculos y diluye las fronteras ${ }^{22}$. Los límites se difuminan y desaparecen, las puertas se abren, las dificultades se allanan. Es lo que Castells ha denominado la sociedad red: una sociedad construida por la revolución de las tecnologías de la información y la reorganización del capitalismo. La sociedad red representa un nuevo modelo de organización socioeconómica mediante la globalización de las actividades económicas y el desarrollo de un sistema de medios de comunicación omnipresentes, interconectados y diversificados. La acción combinada de estos elementos ha provocado una "transformación de los cimientos materiales de la vida, el espacio y el tiempo, mediante la constitución de un espacio de flujos y del tiempo atemporal"23. El capitalismo se expande a ritmo de vértigo, los intercambios se multiplican, y el dinero se mueve por los circuitos virtuales de la telemática: nuevos flujos financieros que escapan a todo control. En este escenario, los Estados-nación pierden de manera alarmante su propia capacidad de dirección, de regulación y de control sobre los procesos socio-económicos. Estamos, como ha recordado Ianni, ante una "crisis generalizada del estado-nación"24.

Y es que, como ha apuntado Capella, esos nuevos fenómenos históricos sintetizados en el término globalización, "desgarran el tejido conceptual de la "teoría política" moderna"25. La teoría política tradicional ha perdido capacidad explicativa ante el empuje de este vasto conjunto de fenómenos que limitan fácticamente el propio ámbito de actuación del Estado como actor principal del orden jurídico-político: “Estos límites 
son impuestos por la concentración y la transnacionalización del poder económico, en el pasado enormemente fragmentario. La mundialización subvierte el mercado "nacional", uno de los fundamentos del poder del Estado-Nación"26.

\section{LA GESTIÓN DEL RIESGO EN LA ERA DE LA GLOBALIZACIÓN}

Vivimos, por tanto, un periodo complejo, de cuestionamiento profundo de formas civilizatorias y culturales en un escenario de cambios vertiginosos y de acoso a los pilares del proyecto ilustrado, que se agudiza ante la evidencia de que las transformaciones culturales que se están operando en nuestro mundo nos conducen hacia una realidad desconocida que precisa, también, nuevos paradigmas. En esas coordenadas, justamente, han irrumpido con fuerza en las últimas décadas, las tesis postmodernas y las nuevas versiones del relativismo, auspiciadas por determinadas variantes del multiculturalismo y del pluralismo jurídico ${ }^{27}$ que, a pesar de sus diferentes fuentes teóricas y sus matices diferenciales, confluyen en la crítica acerba a los grandes metanarraciones de la modernidad, asociadas al discurso universalista sobre los derechos humanos.

Veamos, a continuación, en qué medida el cuestionamiento general de la razón ilustrada, asociado a los cambios tecnológicos que están alterando drásticamente las relaciones del hombre con la naturaleza y transmutando de manera decisiva nuestra imagen del mundo, alcanzan a nuestra comprensión del derecho moderno, particularmente, en relación con el paradigma de los derechos humanos y la protección del medio ambiente, y en qué sentido aquel debe ser redefinido en las coordenadas de la sociedad del riesgo global -acogiéndonos a la terminología con la que Ulrich Beck ha caracterizado la era presente-.

La actual reacción contramoderna ataca desde sus cimientos a la razón, como posibilidad teórica de abstraer y universalizar, estableciendo, en el ámbito jurídico-político, principios generales de convivencia y organización. Aquí podríamos invocar a Erhard Denninger quien no 
duda en aseverar que esta reacción contra el proyecto de la modernidad puede caracterizarse como una "crisis generalizada de la razón", incluso podría hablarse sencillamente del "final de la razón en general". Este es el elemento principal en base al cual se puede justificar la separación entre el derecho de la época de las luces y la Revolución francesa y el actual derecho postmoderno. Lo que caracteriza, pues, a este nuevo derecho es, más que la desaparición de la razón teórica, el declive de la razón práctica como elemento constitutivo del sabery del hacer humanos que posibilita alcanzar compromisos universales. La pérdida de esta orientación capital de la modernidad tiene su causa en el crecimiento de los niveles de inseguridad en las sociedades contemporáneas, que afecta al desarrollo del saber científico, provocado fundamentalmente por tres circunstancias, que expone el profesor de Frankfurt:

a) La primera de ellas es el creciente nivel de riesgo en el manejo de los medios técnicos que los avances científicos han proporcionado; nivel de riesgo que provoca inseguridad. No se conocen bien las consecuencias de nuestros propios actos en el manejo de las tecnologías y existe una sensación general de desprotección ante eventuales catástrofes tecnológicas. Hemos creado una tecnología altamente sofisticada que a veces no somos capaces de dominar, lo cual genera inseguridad. Esto nos conduce necesariamente a lo que Beck ha denominado sociedad del riesgo que supone la obsolescencia de la sociedad industrial. Se trata de una fase de desarrollo de la sociedad moderna en la que los riesgos sociales, económicos, políticos e individuales escapan de forma creciente al control de las instituciones y de las estructuras. Paulatinamente, los peligros de la sociedad comienzan a dominar los debates y conflictos públicos y privados. Como consecuencia de ello son las instituciones las que sufren una crisis profunda de legitimación al convertirse en productoras de amenazas que no pueden controlar. La modernización genera así una tendencia incontrolable que conduce a una nueva situación: la de la obsolescencia de la sociedad industrial para controlar y someter las tendencias que ella misma ha creado. De este modo, el concepto de sociedad del riesgo plantea una transformación en tres áreas: a) la relación de nuestra sociedad con los recursos de la naturaleza y de la cultura, que están siendo dilapidados bajo el torbellino de la razón 
instrumental; b) los paradigmas sociales de seguridad, que están siendo desbordados por la dinámica de un riesgo que no puede ser neutralizado; c) el agotamiento de los referentes significativos de los grupos sociales que han estructurado nuestra sociedad (p.e., conciencia de clase, fe en el progreso, etc...), cuyo derrumbamiento genera indefinición y anomia ${ }^{28}$.

b) La segunda circunstancia está constituida por lo que Denninger llama "explosión de ignorancia", que constituye una de las características constitutivas del saber posmoderno, y cuyas consecuencias afectan a la estructura del Estado de Derecho y a la función del "Derecho regulador". La ampliación de los horizontes de conocimiento en el campo del saber científico implica, paralelamente, la ampliación del horizonte de desconocimiento, en la medida en que, cuanto más se sabe, más consciente se es de lo mucho que resta aún por saber. Las incertidumbres amenazan incluso la estabilidad del conocimiento pretendidamente seguro; y esta paradoja afecta no sólo a zonas marginales de la ciencia, sino que repercute sobre ámbitos de relevancia técnica inmediata (por ejemplo, ¿cuáles serán las consecuencias a medio plazo de los cambios climáticos o del agujero de la capa de ozono?; ¿volverá a repetirse en algún otro rincón del planeta una catástrofe como la de Chernobyl?; ¿qué riesgos implican para el futuro de la humanidad los nuevos avances en genética?).

Para ilustrar algunos de los anteriores interrogantes, Denninger cita una sentencia del Tribunal de lo Contencioso-Administrativo de Kassel en la que, al considerarse la necesidad de obtener licencia para unas instalaciones experimentales de manipulación genética, el Tribunal decide dejar a un lado los mecanismos tradiciones de argumentación propios del Estado de Derecho. En vez de recurrir a la teoría de la norma general excluyente, en virtud de la cual al no estar expresamente prohibida dicha actividad debe entenderse permitida, además de tener en cuenta que dicha conclusión se deduce de la aplicación de ciertas libertades constituciones (como las de ejercer oficio y actividad económica); el juez se transforma en legislador estableciendo un "programa de seguridad preventivo" y, en virtud de ello, prohíbe la actividad, invirtiendo la relación prohibido-permitido, de la siguiente forma: "Puesto que la puesta en práctica de este tipo de actividades no está expresamente permitida, 
sino condicionada a severos controles, debe estar en principio prohibida en función de sus imprevisibles riesgos". Y al hace esto el juez crea un amplio margen de inseguridad, ya que el ciudadano se vería abocado a la incertidumbre a la hora de someter a la consideración de los tribunales la evaluación de cualquier actividad de tipo técnico ${ }^{29}$.

Las consecuencias de este fenómeno se miden en términos de "crisis del Estado de Derecho", en la medida en que los medios tradicionales de aplicación e interpretación del derecho se revelan inútiles. Si no puede determinarse con exactitud el causante de un daño, si tampoco puede delimitarse el hecho jurídico como consecuencia del cual nace la responsabilidad, ¿de qué sirve entonces el "derecho regulador"? Se desdibujan entonces los límites aparentemente claros entre lo prohibido y lo permitido. Al difuminarse el límite entre seguridad y previsibilidad del derecho y, con él, la libertad y responsabilidad del ciudadano, cambiaría igualmente la seguridad precaria, preventiva, manipulable y contextual en relación a determinados bienes jurídicos. Y con ello, "la relación entre la generalidad de la Ley, entre el sujeto responsable de sus actos... y la superación técnico-racional del mundo, dicha relación todavía brillaría un último segundo con todo su esplendor, justo en el momento de su desaparición" 30 .

c) la última circunstancia afecta a la relación saber-poder, que se ha visto considerablemente redimensionada por la creciente influencia de los avances científico-técnicos en la concreción de estructuras de poder en la sociedad. En consecuencia, se puede detectar una creciente implicación de las estructuras de poder y del desarrollo científico, lo cual tiene una dimensión cotidiana: la desintegración de los modelos tradicionales de identidades colectivas como el Estado nacional, la clase social, la creencia religiosa o el partido político. Como consecuencia de esta redefinición de la relación saber-poder hay categorías básicas del pensamiento jurídico-político que precisan ser repensadas ${ }^{31}$.

No podemos seguir ignorando que tenemos una mutación importante ante nosotros, una mutación que exige un cambio de perspectivas y de instrumentos para pensar el modelo de sociedad y de derecho que queremos para el futuro. Y realmente esta mutación afecta al saber de nuestro tiempo, como pone de manifiesto Denninger. Ya no nos 
sirven muchas de las categorías tradicionales que conforman el Estado de Derecho y el sistema jurídico al que dio a luz la modernidad. En algún sentido, sus conceptos precisan ser reformulados. La imaginación del jurista y del teórico del derecho tiene que realizar esfuerzos creativos si no queremos quedarnos anclados en un saber que está comenzando a dejar de ser útil para explicar y resolver los grandes problemas a los que nos enfrentamos; problemas a escala planetaria cuya dimensión temporal rebasa los confines del presente; los nuevos problemas que el derecho ha de afrontar hablan de espacios sin fronteras, casi podríamos decir sin horizontes, y de tiempos que están por venir. Ya no son problemas de nuestra sociedad, de nuestro país o de nuestra generación, las más acuciantes demandas a las que el derecho habrá de ir dando respuesta tienen con frecuencia un alcance geográfico mundial y afectan no sólo a nuestra generación sino a las generaciones venideras. Si el derecho de la modernidad incorporó la dimensión de progreso en la contemplación del presente, desde una perspectiva de optimismo antropológico; nosotros, si queremos preservar ese optimismo, deberemos incorporar la dimensión global de los problemas en la contemplación del futuro.

\section{LA PROTECCIÓN DE LOS DERECHOS EN LA SOCIEDAD DEL RIESGO}

En este contexto se hace cada vez más patente que la globalización entraña desafíos de singular relevancia en el proceso de desenvolvimiento histórico de los derechos humanos que atraviesan, en este periodo de redefinición de las ciencias sociales en general, un momento particularmente crítico. La intensificación de los intercambios económicos a través de las nuevas tecnologías, la expansión frenética del capitalismo y la creación de macropoderes económicos transnacionales, inaccesibles al control democrático de la ciudadanía, ponen de manifiesto una nueva fase de desarrollo del capitalismo que plantea retos también nuevos para la teoría de los derechos humanos ${ }^{32}$. La eclosión del nuevo orden económico global hace cada vez más evidente la crisis de todo un modelo de comprensión de los derechos humanos como categorías 
vinculadas espacio-temporalmente, cuya satisfacción excluyente queda restringida al limitado espacio estatal y a la dimensión temporal del presente. Puede decirse que la globalización inaugura una nueva fase en el decurso histórico de los derechos humanos; una fase marcada por la demanda de una comprensión cabal y completa de los derechos humanos como categorías insertas de lleno en la realidad histórica en la que se explicitan. Si hasta ahora los derechos humanos han sido concebidos de forma fragmentaria y parcial, el horizonte de la globalización exige superar esta suerte de planteamientos estancos e incompletos que son la causa de muchos dislates en el desarrollo doctrinal de los derechos humanos.

Asistimos, por tanto, a una crisis del paradigma espacio-temporal de los derechos humanos, cuya insuficiencia se hace cada vez más patente al constatarse que la universalización de los derechos humanos resulta incompatible con ese paradigma. ¿Cuáles son los elementos de ese paradigma cuya vigencia constituye hoy un importante obstáculo teórico a la realización universal de los derechos humanos? En mi obra En las Encrucijadas de la modernidad, sostuve, a propósito de la crisis del paradigma jurídico de la Ilustración, la necesidad de una reformulación del paradigma jurídico que reconciliara la racionalidad de los fines con la racionalidad instrumental y que allanase el camino a una concepción de la justicia que superase el reducido marco de las fronteras estatales. Al hilo de ello argumenté que el derecho moderno debía liberarse de algunos lastres que impedían soltar amarras en esa nueva travesía que había que iniciar. Parece conveniente ahora volver sobre lo que expuse entonces para retomar dos aspectos principales que cobran inusitada importancia en este momento y que, aplicados a la teoría de los derechos humanos, constituyen los ejes de ese paradigma espacio-temporal cuya crisis resulta, a mi juicio, innegable:

a) En primer lugar, es necesario superar el reducido espacio de las fronteras estatales. En los tiempos de la globalización, el marco político estatal se revela cada vez más insuficiente. Constituye un lugar común la afirmación, popularizada por Daniel Bell, en virtud de la cual en la era contemporánea el Estado resulta demasiado grande para las cosas pequeñas y demasiado pequeño para las cosas grandes. Refiriéndose a 
esta cuestión, Beck ha afirmado que asistimos al ocaso de una premisa esencial de la primera modernidad, aquella que vinculaba la acción a espacios delimitados geográficamente en los contornos del Estado-nación. La globalización, puntualiza el sociólogo germano, entraña la disolución de las acotaciones territoriales, el fin de las fronteras y de las separaciones artificiales. Todo aparece ya interconectado: la economía, la información, la ecología, la técnica, los conflictos transculturales y la sociedad civil: "Así entendida, la globalización significa la muerte del apartamiento, el vernos inmersos en formas de vida transnacionales a menudo no queridas e incomprendidas"33. En este contexto, se hace necesario implementar estructuras institucionales de ámbito supranacional que permitan dar respuesta a problemas que van más allá de las reducidas fronteras del Estado-nación. Subrayaba, entonces, la necesidad de superar la dispersión de los múltiples centros jurídicos estatales, respondiendo a las pulsiones globales con un esfuerzo universalizador que permitiera contrarrestar las tendencias negativas ${ }^{34}$ que el proceso de globalización comporta, desde una óptica de reconocimiento de las aportaciones de la modernidad jurídicas, cuyos elementos determinantes representan, al decir de Streck, "marcos civilizatorios insuperables"35.

En lo que concierne a la teoría de los derechos humanos el horizonte espacial de la modernidad ha generado una concepción de los derechos humanos estrictamente vinculada al Estado-nación que, al apostar por la realización de los derechos de los ciudadanos, sacrifica su propia matriz ilustrada de cuño universalista. Los derechos humanos quedan, en consecuencia, indisociablemente unidos al marco geográfico circunscrito por el principio de soberanía nacional, tanto al nivel interno de cada Estado como en el escenario inter-nacional en el que el Estado sigue apareciendo como el principal actor del orden jurídico-político. De este modo, la realización de los derechos humanos es contemplada como una tarea fragmentaria y excluyente que descansa sobre la afirmación dogmática de la soberanía nacional como límite en la realización de los derechos ${ }^{36}$. Por otra parte, la emancipación del sistema económico convierte a los Estados en instrumentos serviles del capitalismo transnacional. El contexto internacional se puebla, así, de un conjunto de Estados en liza que pugnan entre sí por cumplir las demandas y expectativas de sus 
nacionales con respecto a la realización de los derechos fundamentales constitucionalmente proclamados. Huelga decir que el escenario internacional se convierte en un campo de batalla en el que los Estados tratan de satisfacer a toda costa las expectativas de bienestar y desarrollo de sus ciudadanos, en detrimento, si necesario fuere, de los derechos de otros nacionales. La lógica de la racionalidad económica se convierte, entonces, en la pauta que los Estados adoptan para la realización de los derechos. Presa de esa frenética voracidad posesoria del capitalismo global, los Estados se convierten en depredadores contumaces de otros Estados en el ámbito de la economía global. Y así, los países ricos logran altos niveles de bienestar al precio de la privación y la miseria de los países más pobres. De esta suerte, la satisfacción de los derechos entra en una dinámica excluyente que se agudiza cuando se contempla, como ha puesto de relieve Mercado, la existencia de "derechos insostenibles", por cuanto que propician actitudes y comportamientos lesivos para la preservación del medio ambiente. El deterioro del medio ambiente, la contaminación y la disposición de los recursos no renovables no pueden encontrar justificación en interpretaciones atomistas de determinados derechos como la propiedad, la libre circulación de mercancías o la libertad de empresa ${ }^{37}$.

b) En segundo lugar, la dimensión temporal de los problemas propia del derecho moderno supeditaba la constatación del conflicto a su concreta configuración en el presente, de modo que un bien jurídico sólo se consideraba lesionado ante un daño real y efectivo. Las circunstancias de la innovación tecnológica en nuestras sociedades convierte en tema de indudable actualidad el nivel de riesgo en el manejo de los avances tecnológicos. Nuestras sociedades comienzan a ser conscientes de los riesgos imprevisibles que se pueden derivar del uso de las nuevas tecnologías, que pueden poner en peligro la propia continuidad de la especie y la preservación del planeta. Surge entonces, como ya afirmé en otro lugar, la necesidad de incorporar una mirada ecológica hacia nuestro entorno que haga posible la reconciliación del hombre con su hábitat natural: nuestros problemas no se miden ya en términos de lesiones actuales y efectivas a los bienes jurídicos, sino que exigen la incorporación de una dimensión futura. Subrayaba, entonces, la 
necesidad de incorporar la dimensión de futuro en la catalogación de los conflictos jurídicos si queremos resolver las grandes interrogantes que afectan al género humano. Frente a la causación del daño y a su eventual reparación, hemos de oponer un derecho de prevención de riesgos que, anticipando la dimensión temporal del futuro, salvaguarde el interés, no por difuso menos digno de protección, de las generaciones futuras a una vida digna ${ }^{38}$. Este planteamiento enlaza con la necesidad, apuntada por Erhard Denninger, de impulsar un derecho de prevención de riesgos, en consonancia con las amenazas imprevisibles que se ciernen sobre la humanidad toda. Las secuelas del desarrollo científico-tecnológico repercuten en el sistema jurídico, que se ve abocado a articular respuestas de carácter preventivo que eviten la causación del daño. En términos de derecho ambiental ya no es suficiente el principio en virtud del cual "quien contamina paga". No se trata de reparar el daño porque en muchos casos es irreparable: la pérdida de la diversidad biológica, la contaminación de los ríos, el calentamiento global del planeta, el agujero de la capa de ozono o la contaminación de los acuíferos subterráneos, son sólo algunos ejemplos de las amenazas reales que se derivan de este uso incontrolado de los avances científico-tecnológicos ${ }^{39}$.

Este tiempo convulso de la globalización inaugura una era trepidante en la que los acontecimientos se suceden a velocidad de vértigo. Una existencia convertida en devenir nos precipita sobre el abismo de la pérdida de referentes. Es la quiebra del paradigma temporal de la modernidad vinculado al presente: un proceso de "desreferencialización" temporal que nos hace sensibles a incertidumbres inquietantes, que nos deja inermes ante amenazas y riesgos nunca antes conocidos. Las innovaciones científico-tecnológicas incrementan la sensación de desasosiego y de zozobra. Es la "sociedad del riesgo mundial" 40 acuñada por Beck: una sociedad que se sabe vulnerable, en la que las amenazas se prolongan temporalmente hacia el futuro. Somos conscientes de que las tecnologías son portadoras de riesgos imponderables e imprevisibles y nos sentimos inseguros. Una sensación global de precariedad ante estas amenazas más que potenciales nos une a nuestros congéneres en una reacción solidaria de cuño cosmopolita. La demanda creciente de seguridad nos proyecta hacia el futuro, en un afán por perpetuar la vida 
y por preservar el planeta, y surgen, entonces, "intereses difusos" que reclaman protección. En la sociedad del riesgo todo aparece difuminado: "los denominados peligros globales hacen que se resquebrajen los pilares del tradicional sistema de seguridad. Los daños pierden su delimitación espacio-temporal para convertirse en globales y permanentes. Los daños apenas si se pueden seguir atribuyendo a unos responsables determinados; el principio de causalidad pierde capacidad segregadora" 41.

\section{LA UNIVERSALIZACIÓN DE LOS DERECHOS HUMANOS Y LA JUSTICIA INTERGENERACIONAL}

Sensible a esta demanda de seguridad y a la preocupación creciente por la preservación del medio natural y de las condiciones que permitan la continuidad de la especie, la Corte Internacional de Justicia ha venido elaborando una concepción de equidad intergeneracional basada en los derechos equitativos de las generaciones futuras a un medio ambiente sano y equilibrado, cuya preservación sea compatible con el desarrollo tecnológico. Precisamos incorporar una concepción intergeneracional de la justicia a nuestra forma de pensar el desarrollo, la competitividad y la productividad. De lo contrario, el daño ambiental puede tener consecuencias irreparables para el desarrollo de las condiciones que permitan una existencia digna. Afrontar el reto de construir un modelo de competitividad sostenible es una necesidad inaplazable. La idea de justicia intergeneracional parte, a tenor de Edith Brown, del reconocimiento de que cada generación es depositaria de un legado natural y cultural que ha recibido de las generaciones precedentes y que ha de transmitir a las generaciones futuras. Esta relación impone ciertas obligaciones planetarias al tiempo que brinda a cada generación ciertos derechos planetarios, en tanto que beneficiarios del fideicomiso recibido de sus antepasados. La autora propone tres principios básicos de equidad intergeneracional, a saber:

a) cada generación debe ser compelida a conservar la diversidad de recursos naturales y culturales y tiene, derecho, además, a una diversidad comparable a la de las generaciones precedentes. Una restricción en este 
sentido afectaría a las opciones disponibles a las futuras generaciones (principio de conservación de opciones);

b) cada generación está obligada a preservar la calidad del planeta tal como lo ha recibido de las generaciones precedentes (principio de conservación de la calidad);

c) cada generación debe proporcionar a sus miembros derechos equitativos de acceso al legado de generaciones pasadas, preservando este derecho para generaciones futuras (principio de conservación de acceso $)^{42}$.

De este modo, el concepto de justicia intergeneracional comporta un compromiso con la especie y una reconciliación del hombre con su hábitat natural $^{43}$. A través de diversos pronunciamientos jurisprudenciales ha ido adquiriendo carta de naturaleza una concepción vertical de la justicia que vincula a las generaciones presentes con las generaciones futuras y de la cual surgen obligaciones, reglas y actitudes "basadas en un concepto de distribución equitativa que era a la vez horizontal en relación con la generación actual y vertical en cuanto al beneficio de las generaciones futuras" ${ }^{44}$. En un pronunciamiento posterior se afianza la línea jurisprudencial ya iniciada. Nos referimos al caso de las pruebas nucleares de Francia en el Pacífico Sur que fue objeto de demanda por parte de Nueva Zelanda. En este supuesto, la C.I.J. declinó su jurisdicción por tratarse de pruebas subterráneas en lugar de atmosféricas. Sin embargo, el juez Weeramantry manifestó en voto particular su convicción de que la Corte tenía la obligación de tutelar los derechos de las generaciones futuras, arguyendo expresamente que "Esta Corte debe considerarse fiduciaria de los derechos de esas futuras generaciones de la misma manera que un tribunal doméstico actúa como fiduciario de los derechos de un niño incapaz de valerse por sí mismo. El reclamo de Nueva Zelanda en cuanto a que sus derechos se ven afectados no se relaciona solamente con los derechos de las personas que existen actualmente; los derechos del pueblo de Nueva Zelanda incluyen también los derechos de las personas por nacer, a los que una nación tiene el derecho y, ciertamente, también el deber de proteger" 45.

Y a propósito de la amenaza del uso de armas nucleares la Corte aludió implícitamente a la quiebra del paradigma espacio-temporal al 
estimar, en opinión consultiva, que "el poder destructivo de las armas nucleares no puede ser contenido ni en el tiempo ni en el espacio. Ellas tienen el poder de destruir toda la civilización y la totalidad del ecosistema del planeta". Y más adelante, la Corte dilucida la relevancia jurídica de la cuestión al estimar que el derecho de las generaciones futuras es merecedor de una tutela jurídica adecuada: “...[a] fin de aplicar correctamente al presente caso las normas de la Carta sobre el uso de la fuerza y el derecho aplicable en los conflictos armados, particularmente el derecho humanitario, resulta imperativo para la Corte tomar en cuenta las características únicas de las armas nucleares y en particular... su capacidad para perjudicar a las generaciones futuras ${ }^{\prime 46}$.

Más recientemente, el Institut de Droit International se ha pronunciado sobre la necesidad de incorporar elementos de una equidad intergeneracional al discurso jurídico, al proclamar, en una resolución sobre responsabilidad por daño ambiental, que "el derecho ambiental internacional está desarrollando importantes nuevos lazos con el concepto de la equidad intergeneracional... (que)...están influyendo en las cuestiones relativas a la responsabilidad" ${ }^{27}$.

En suma, la reconciliación del hombre con el medioambiente a través del derecho requiere, como ha indicado Serrano, un esfuerzo por descomponer el sistema jurídico para buscar nuevos instrumentos de protección y de tutela. La nueva perspectiva de análisis exige situar los problemas en "el vector complejo que relaciona ecología, espacio, tiempo y derecho en el contexto de la crisis ecológica como crisis civilizatoria". Debe quedar claro, sin embargo, que, pese a la incardinación de estas cuestiones en un nuevo paradigma temporal, su alcance afecta de lleno a la ordenación espacial del poder jurídico-político, en la medida en que los problemas medioambientales trascienden con frecuencia el reducido marco de las fronteras estatales. Un tratamiento de estos problemas demanda una consideración global que permita adoptar soluciones efectivas al nivel supra e infraestatal. Es necesario, pues, pensar, simultáneamente, en una estrategia de centralización y descentralización que permita adecuar los espacios de validez y vigencia en función de la propia delimitación geográfica de los ecosistemas ${ }^{48}$. 


\section{UN NUEVO PARADIGMA DE LOS DERECHOS HUMANOS}

Entiendo que la comprensión de los derechos humanos como categorías temporalmente vinculadas al presente cercena el estatuto de las libertades al vaciarlas de su valor proyectivo. Es cierto que la modernidad inauguró una concepción del tiempo como tiempo presente. Y es cierto también que, en consecuencia, el derecho moderno excluyó del ámbito de la juridicidad, por regla general, los hechos, actos o acontecimientos que no se hubieran actualizado en la realidad social. La aplicación de una norma requería entonces la plena materialización social del supuesto de hecho. Y la titularidad de los derechos no quedó al margen de esta comprensión moderna de la temporalidad, por lo que, salvo muy contadas excepciones, la imputación de derechos y deberes requería una existencia individual y concreta. Nos desviaríamos de nuestro propósito si nos entretuviésemos en el análisis pormenorizado de esta cuestión. Sólo nos interesa destacar que la interdependencia global de este mundo tecnológicamente hiperdesarrollado exige incorporar la visión del futuro a la teoría de los derechos humanos, redimensionando con ello esa dimensión utópica que es consustancial a los derechos humanos y reivindicando también su valor emancipatorio. Dos aspectos que pueden conciliarse definitivamente en una concepción proyectiva de los derechos humanos: aquella que sin abjurar del valor de las conquistas históricas y sin rehusar su compromiso con su realización actual en aras de la emancipación de individuos concretos, proyecta su potencial hacia el futuro, consciente de que los derechos humanos sólo serán si se construyen para todos, los que son y los que están por venir.

Frente a la crisis del paradigma espacio-temporal de los derechos humanos, férreamente vinculado al espacio geográfico del Estadonación y a la dimensión temporal del presente, reivindicamos un nuevo paradigma espacio-temporal basado sobre la comprensión global de los derechos humanos de alcance planetario y sobre la apertura de los derechos humanos hacia el futuro, mediante la protección de intereses difusos de titularidad colectiva que deben ser adecuadamente protegidos. Esos intereses difusos, como sostiene Reich, tienen el carácter de bien público y atañen a la calidad de vida global ${ }^{49}$. En este contexto, justamente, 
la categoría de derecho subjetivo, en cuanto elaboración conceptual de la dogmática individualista burguesa, resulta abiertamente inadecuada en la medida en que propicia la identificación de los derechos fundamentales y los derechos patrimoniales acentuándose el énfasis apropiatorio que implica las ideas de exclusividad, de singularidad y de disponibilidad. Frente a ese concepto, de honda raigambre formalista y larga tradición en la dogmática jurídica positivista, es necesario reafirmar el carácter inclusivo, universal e indisponible de los derechos, escindiendo el nexo entre derechos fundamentales y derechos subjetivos ${ }^{50}$.

No huelga soslayar, como ha significado Serrano al referirse al estatuto jurídico de los derechos medioambientales, que la categoría de derecho subjetivo está hondamente marcada por la apropiación capitalista en términos excluyentes, como fundamento del orden capitalista y arquetipo de los derechos de propiedad: "Esto -sostiene el que fuera catedrático de la Universidad de Granada- es justo lo contrario de lo que necesitamos para proteger recursos naturales que en nuestro sistema de mercado son bienes comunes, de libre disposición, difusos y gratuitos" ${ }^{51}$.

Al postular un nuevo paradigma de los derechos humanos apostamos, por tanto, por la superación de las visiones localistas, pacatas y alicortas, territorialmente ancladas en los límites territoriales del Estado; rechazamos, simultáneamente, la concepción individualista de los derechos con su marchamo excluyente y apropiatorio y postulamos, finalmente, la necesidad de una distribución equitativa de los derechos y de los bienes comunes que contemple una perspectiva intergeneracional. Ello nos abre, en opinión de Ferrajoli, un nuevo horizonte para el constitucionalismo y el garantismo, al proyectar el paradigma constitucional hacia el futuro para concebirlo como un modelo a largo plazo, además de global, que se sustancia: a) en un constitucionalismo de derecho privado, capaz de establecer reglas y vínculos para los poderes económicos privados; b) en un constitucionalismo de derecho internacional, pues las agresiones al medio ambiente alcanzan dimensiones globales y precisan ser combatidas en el escenario internacional, introduciendo normas, límites, vínculos, controles, funciones e instituciones de garantía a nivel planetario; c) por último, es necesario afrontar el problema energético que amenaza con colapsar la economía del planeta 
apostando por las energías limpias. Ese garantismo global de los bienes fundamentales requiere el desarrollo de una esfera pública planetaria y la creación de una política global, basada en la cooperación mundial y garante de un interés público general ${ }^{52}$.

La construcción de ese nuevo paradigma es, en virtud de lo expuesto, una demanda inaplazable a la que la doctrina habrá de ir dando respuesta en años venideros. Se trata de comprender que los derechos no son apropiaciones "espacio-temporales", sino que representan una suerte de catálogo ético sobre el cual transformar el presente y cimentar un futuro más esperanzador, que no puede descansar sobre la exclusión ni sobre el uso indiscriminado e irresponsable de los recursos naturales. Y ello requiere, sin duda, la superación de las concepciones autopoiéticas de cuño sistémico y la ampliación del horizonte teórico hacia perspectivas interdisciplinares. Conviene precisar que este nuevo paradigma espacio-temporal de los derechos humanos no prescinde de su concreta incardinación histórica ni puede contemplarse como una estrategia de desplazamiento de los viejos derechos de titularidad individual; antes bien, este nuevo paradigma es plenamente fiel a las conquistas históricas de los derechos humanos y a su configuración generacional, pero trata de superar la vieja concepción formalista de los derechos humanos heredera de la concepción del positivismo legalista- que los reducía a su comprensión en términos individualistas y erigir progresivamente a los derechos humanos como el catálogo ético de la nueva era global. La humanización del derecho reclama la capacidad expansiva de los derechos humanos más allá de las fronteras territoriales y del tiempo presente ${ }^{53}$.

Es obligado notar que el nuevo paradigma espacio-temporal representa, en consecuencia, un paso decisivo en la reconciliación de los derechos humanos con el legado de la modernidad y con la exigencia de universalidad de los mismos que es, como apunta Carrillo-Salcedo, elemento constitutivo y definitorio de los derechos humanos ${ }^{54}$; una especie de segunda modernidad en la que ésta quedaría simultáneamente superada y purificada de sus contaminaciones teóricas, en la línea de la propuesta de Habermas que aboga por la plena realización del proyecto moderno. Se trata, en suma, de una apuesta por la conciliación 
entre modernidad y modernización, entre derecho y justicia, entre globalización y universalización de los derechos humanos cifrada en dos tesis principales:

1‥ Los derechos humanos de los ciudadanos no pueden realizarse a costa de los derechos humanos de los infraciudadanos: la teoría de los derechos humanos debe salir del impasse teórico de su encuadre estatalnacional que lo enmarca férreamente en el ámbito de los ordenamientos estatales. Un nuevo paradigma de los derechos humanos debe superar las angostas limitaciones geográficas, tan falsas como inconmovibles, en aras de una comprensión global de los derechos en el completo marco espacial de un mundo interdependiente. El Estado, afirma Pureza, ya no es un instrumento institucional suficiente para dar respuesta a problemas fundamentales de amplitud planetaria. Existe una conciencia, cada vez más sólidamente arraigada, de la dimensión planetaria de la emancipación, "la conciencia de que la humanidad no es un puro mosaico de Estados igualmente soberanos, sino más bien una comunidad de personas y de pueblos que están enfrentados a fenómenos múltiples de dominación individual y colectiva"55.

Se trata, entonces, de abandonar el espacio inter-nacional como campo de batalla en el que los intereses económicos dirimirán el grado de satisfacción de los derechos, como si éstos pudieran ser objeto de apropiación sin ser estragados. Los derechos no pueden ser el fruto de las conquistas mercantiles en el ring de la economía, porque éste es un combate sin reglas, asimétrico, desigual e inicuo. La fuerza normativa de los derechos no puede quedar supeditada a una victoria trucada, que condena a la miseria a tres cuartas partes de la población mundial. La globalización plantea así un desafío que no podemos eludir: seguir entendiendo los derechos humanos como subproductos político-culturales objeto de apropiación o, por el contrario, abandonar los esquemas de una realización parcial y fragmentaria, condensada en el modelo estatal-nacional, para dar paso a una concepción omnicomprensiva de los derechos humanos que contemple los problemas en su radical complejidad, como algo que concierne a la humanidad toda.

2a. En segundo lugar, los derechos humanos de la generación presente no pueden realizarse a costa de los derechos humanos de 
las generaciones futuras: se hace preciso superar el marco temporal de referencia de los derechos humanos como categorías jurídicas sumergidas de lleno en el presente. Esta concepción moderna de la temporalidad ha sido malévolamente utilizada en tiempos recientes para dar fundamento a una concepción truncada de los derechos humanos como principios legitimadores del statu quo vigente y como estrategias puramente instrumentales de pacificación social. La recuperación de la doble dimensión emancipatoria y utópica de los derechos humanos exige la incorporación de ambas en una dimensión proyectiva. Derechos que son de todos y que a todos alcanzan. Por eso, deben materializarse históricamente en la experiencia concreta de los hombres, emancipándolos de las circunstancias que constriñen su pleno desarrollo como personas y que atacan a su dignidad; pero, al mismo tiempo, esa concreción en el presente no puede sacrificar las expectativas de una realización cada vez más completa de estos derechos en el futuro. La dimensión proyectiva comporta entonces un compromiso de la doctrina por una contemplación total del proceso histórico en el que los derechos humanos se despliegan.

En la era de la globalización, sin embargo, el progreso moral de la humanidad ha quedado ya indisociablemente unido a la creación de las condiciones que permitan el disfrute efectivo de los derechos: la superación de una concepción periclitada de los derechos humanos trae a colación el desafío ineludible de su universalización. La incorporación de un nuevo paradigma espacio-temporal de los derechos humanos es un aldabonazo a ese imperativo ético que se hace sentir cada vez con más fuerza y del que cada vez resultará más difícil escapar. Quizás porque la globalización comporta una mutación profunda de nuestra percepción del mundo y de la ordenación de las relaciones sociales, económicas y políticas, se hace cada vez más evidente la existencia precaria de los derechos humanos; una existencia que no se mide, precisamente, por el grado de eficacia y de respeto, sino por la insuficiencia jurídica e institucional para hacerlos efectivos, una existencia que es puesta en cuestión de continuo por la alarmante cantidad de violaciones flagrantes que se producen en todos los rincones del planeta. Por eso, esa sensación de precariedad está alimentando una demanda creciente 
de eficacia que se siente cada vez con más fuerza y que adquiere tantas veces tintes dramáticos. La globalización hace cada vez más evidente la contradicción entre el progreso técnico-económico y el progreso moral, entre la modernización capitalista y la modernidad filosófico-cultural, entre la racionalidad de los medios y la de los fines, entre la expansión vertiginosa del capital y la realización de los derechos humanos. Justamente, por ello, la efectiva realización de los derechos humanos en la era de la globalización requiere la superación de un paradigma espacio-temporal cuyo agotamiento resulta cada vez más incontestable y su sustitución por un nueva comprensión de los derechos humanos en las coordenadas espacio-temporales, en aras de la ampliación del horizonte de los derechos a todos los seres humanos, existan o no en este preciso momento histórico.

La era de la globalización inicia una nueva fase en el proceso histórico de despliegue de los derechos humanos. Justamente aquella que concierne a su universalización, a la extensión de los derechos más allá de las fronteras estatales, a la aniquilación de diferencias que obstruyen el avance de los derechos humanos como conjunto de valores universalmente compartidos. Es el momento de que los derechos dejen de ser objeto de apropiación y de que se yergan nuevamente sobre el horizonte sombrío de una humanidad turbada para dibujar los perfiles de una nueva utopía cuya proyección histórica permitirá la conciliación de la racionalidad tecnológica con la racionalidad de los fines, del derecho con la justicia. El progreso moral de la humanidad está vinculado a la capacidad del hombre para hacer efectivo el catálogo ético que representan los derechos humanos. Su plena realización demanda un nuevo paradigma espacio-temporal que supere las barreras convencionales de la política tradicional y que proyecte los derechos más allá del tiempo presente, un paradigma que permita reconciliar al hombre con sus congéneres y a la especie con el planeta. 


\section{NOTAS}

1 Este trabajo ha sido producido en el seno del proyecto de excelencia "Fundamentos teóricos del neoconstitucionalismo: un modelo jurídico para una sociedad global" (DER2016-76392P), financiado por el Ministerio de Economía y Competitividad de España

2 Como ha evidenciado Giovanni Tarello, la ideología igualitaria, al quedar plasmada en un puro igualitarismo formal, quedó reducida a un instrumento técnico de simplificación de los sistemas jurídicos ya que esta igualdad no significó otra cosa que unicidad del sujeto jurídico. Con ello no se abolían las diferencias subjetivas, sino que eran desplazadas a los predicados jurídicos, manteniendo formalmente la igualdad de los sujetos de derecho. Se consumaba así la ficción de un derecho igualitario en concubinato con un orden social y económico inicuo: "El código civil se estructuró sobre el sujeto jurídico único, y transportó las diferencias subjetivas predominantemente en aquel predicado jurídico que es la capacidad de actuar, esto es, de producir efectos jurídicos mediante la voluntad: todos son iguales como sujetos, pero algunos no tienen o no tienen sin la ayuda de otro... la capacidad de actuar. ... El código penal se estructuró sobre el sujeto único...; las diferencias que persisten -y son muchas- se deslizan en los predicados bajo la forma de atenuantesy agravantes de la acción objetivamente descrita" (Tarello, G., Cultura jurídica y política del derecho, F.C.E., México, 1975, pp. 50-51).

3 Kelsen representa la formulación más acabada del positivismo formalista y, por ende, el abanderado de la neutralidad de la ciencia del Derecho que, en su Teoría Pura, se perfila como un sistema autónomo, exclusivamente normativo, que excluye delámbito de lo jurídico las valoraciones como propias de la ética, de la sociología o de otras ciencias humanas o sociales. Ésta es, sin duda, la gran equivocación del positivismo: ¿cómo puede concebirse el derecho en estado puro, ajeno a los valores, a la sociedad, a sus principios y creencias? El profesor Ollero, al abordar la teoría kelseniana, se plantea la misma pregunta: "Pero ¿es realmente posible que una teoría jurídica sea "neutral"? Kelsen hereda toda la temática weberiana sobre la asepsia valorativa en las ciencias sociales e intenta darle cumplimiento. En las ciencias físicas, la peculiar relación sujeto-objeto parece hacerlo viable; en las "humanas", sin embargo, nos parece que sólo un reduccionismo físico lo posibilitaría: un sicólogo será "neutral" en la medida en que neutralice el objeto de su estudio, que deja de ser el hombre para quedar reducido a una sección parcial del mismo. De actuar así, la teoría pura daría paso a una "ideología" (falseamiento de la "realidad") científico-coartante, disponible como instrumento al servicio de la clase dominante de un orden social liberal. Al examinarse la posible asepsia de la teoría pura es todo el positivismo científico-social el que acaba sentado en el banquillo" (Ollero Tassara, A., ¿Tiene razón el derecho? Entre método científico y voluntad política, Congreso de los Diputados, Madrid, 1996, pp. 157-158).

4 Marí, E., "La interpretación de la ley. Análisis histórico de la escuela exegética y su nexo con el proceso codificatorio de la modernidad" en AA.VV, Materiales para una teoría crítica del derecho, Abeledo-Perrot, Buenos Aires, 1991, pp.258-259.

5 Cfr. Ferrajoli, L., Por uma teoria dos direitos e dos bems fundamentais, Livraria do Advogado, Porto Alegre, 2011, p. 17. Ferrajoli abunda en la inadecuada identificación entre derechos fundamentales y derechos patrimoniales que procede, en su opinión, del primer liberalismo y que trae su causa de un equívoco, pues el término "derecho de propiedad" debido a su carácter polisémico sirve para referirse tanto al derecho de ser propietario como al derecho de disponer de los propios derechos de propiedad que es un aspecto de la capacidad jurídicay de la capacidad de obrar reconducible a la clase de los derechos civiles. A esta confusión atribuye el profesor italiano dos subsiguientes equívocos de alcance: en primer lugar, la revalorización del derecho de propiedad en el pensamiento liberal, equiparable a los derechos de libertad y, en segundo lugar, el menosprecio en el seno del pensamiento marxista del concepto de libertad como derecho burgués, por su identificación con el derecho de propiedad (Ferrajoli, L., Por uma teoria dos direitos e dos bems fundamentais, cit. p. 19ss.).

6 Cfr. Marí, E., "La interpretación de la ley. Análisis histórico de la escuela exegética y su nexo con el proceso codificatorio de la modernidad", cit., p. 258. En la línea ya apuntada se pronuncia Tarello, al analizar las ideologías de Pufendorf y Leibniz que, acuñadas en un contexto iusnaturalista, 
tuvieron una influencia decisiva en la conformación del modelo jurídico aséptico y neutro forjado en la codificación bajo la égida del positivismo (Cfr. Tarello, G., Cultura jurídica y política del derecho, cit). Cassirer muestra que algunos de los rasgos de la concepción sistemática del derecho arrancan ya de la filosofía de la Ilustración y, más específicamente, del iusnaturalismo racionalista. Así, el entronque del derecho con los métodos matemáticos se realiza por obra de las aportaciones de Hugo Grocio. Esta nota enlaza con el espíritu del siglo XVII. Con ello, el derecho se desplaza del terreno de lo fáctico, al de lo posible. Abundando en esta idea, Leibniz dará un paso decisivo al afirmar que la ciencia del derecho no depende de hechos sino de demostraciones rigurosamente lógicas: "Porque no es posible sacar de la experiencia qué sean en sí mismos el derecho y la justicia.... Con ésto el derecho se asimila a la aritmética pura porque lo que ésta nos enseña sobre la naturaleza de los números y sus relaciones, implica una verdad eterna y necesaria". Y Pufendorf deducirá que los principios del derecho natural poseen la misma evidencia que los axiomas matemáticos. Este apriorismo del derecho -entendido como la exigencia de que los principios jurídicos fundamentales sean universales e inmutables- caracteriza a la filosofía de la Ilustración. (Cfr. Cassirer, E., Filosofía de la Ilustración, F.C.E., México, 1943, pp. 263 ss. La cita está extraída de la página 264). En los desarrollos posteriores del iusnaturalismo esta idea quedará más acentuada.

7 Para Ollero, el error metodológico principal de la vieja Ciencia Jurídica se centra principalmente en sus presupuestos epistemológicos de partida: la idea de que el Derecho es una realidad objetiva y externa, ajena por completo al sujeto de conocimiento. El conocimiento no es así una tarea aséptica sino que resulta ser finalmente un proceso mediante el cual el objeto se hace vivencia: ya no será nunca más algo externo al sujeto de conocimiento. Por eso, puntualiza Ollero, el Derecho no se ofrece al jurista como un todo acabado, "listo" para aplicar, ni siquiera como una fuente de líquido escanciable. Es algo que el sujeto ha de buscar y que sólo podrá encontrar en la medida en que haya ido haciéndolo con su búsqueda. Por eso, todo conocimiento del Derecho es un crear Derecho y toda Ciencia Jurídica es Política Jurídica (Cfr. Ollero Tassara, A., "Una filosofía jurídica posible", en Interpretación del derecho y positivismo legalista, Edersa, Madrid, 1982, p. 252).

8 A esta cuestión se refiere Capella cuando afirma que "el derecho es un instrumento de poder político cuyo funcionamiento convierte en agentes suyos a sus operadores "técnicos" debido a que exige la adopción de decisiones de individualización y concreción por los juristas de las normas dictadas por el aparato del poder político" (Capella, J.R., "La crisis actual de la enseñanza del derecho en España", en AA.VV., La Enseñanza del Derecho. Seminario de Profesores de la Facultad de Derecho, Institución "Fernando el Católico", Zaragoza, 1985, p. 24).

9 Barcellona, P., "La formación del jurista", cit., p. 44.

10 Eriksson, L., "Tendencias conflictivas en el derecho moderno", en Aarnio, A. et alii, La normatividad del derecho, Gedisa, Barcelona, 1997, p. 125.

11 Carrino, A., "L'Io diviso. Formalismo e nichilismo nella crisi della modernità", en Perlingieri, P. (ed.), Soggetti e norma. Individuo e società, Edizione Scientifiche Italiane, Napoli, 1987, pp. 49-50.

12 Faria, J.E., Direito e Cojuntura, Saraiva-Fundaçao Getulio Vargas, Sao Paulo, 2008.

13 Como consecuencia de ello, se produce una crisis de la morfología piramidal y jerarquizada del ordenamiento jurídico que es suplantada por una estructura de bóveda, que implica confluencia e interacción entre diferentes normatividades, un horizonte en el que la totalidad del sistema se obtiene por un horizonte de estructuras normativas de procedencia heterogénea. Pérez Luño se distancia, de este modo, de las tesis recientes que tienden a explicar la estructura actual del ordenamiento jurídico en clave reticular (Pérez Luño, A.E., "Nuevo derecho, nuevos derechos", Anuario de Filosofía del Derecho, 2016, pp. 34-36).

14 Snyder, F., Global Economics Networks and Global Legal Pluralism, EUI Working Papers, 99/6 European University Institute, Florencia, 1999, p. 6; cfr. También, Faria, J.E., Direito e Cojuntura, cit., passim.

15 Cfr. Ianni, O., A era do globalismo, , 4a edic., Civilizaçao Brasileira, Rio de Janeiro, 1999, p. 11.

16 Cfr. Faria, J.E., O Direito na economia globalizada, 1a reimpr., Malheiros, Sao Paulo, 2000, p. 52.

17 Cfr. Wallerstein, I., The Capitalist World-Economy, Cambridge University Press, Cambridge, 1979. Del mismo autor puede consultarse también Geopolitics and Geoculture, Cambridge University Press, Cambridge, 1991. 
18 Cfr. Faria, J.E., O Direito na economia globalizada, cit., pp. 7-8. Para un análisis de las implicaciones de la globalización en el ámbito de la economía, cfr. De la Dehesa, G., Comprender la globalización, Alianza, Madrid, 2000.

19 El impacto de la globalización sobre los derechos humanos en el ámbito de las relaciones iusprivatísticas a partir de la responsabilidad social corporativa ha sido recientemente estudiado en un interesante trabajo por Belloso Martín, N., "Algunos efectos perversos de la globalización: las empresas transnacionales y el deber de respeto de los estándares mínimos internacionales de derechos humanos", Cuadernos Electrónicos de Filosofía del Derecho, 28, 2013. Disponible en: https://ojs.uv.es/index.php/CEFD/article/view/2649/2644 . Acceso el 02.10.2016.

20 Con indiscutible fuerza expresiva, Bauman ha reflejado esta situación en los siguientes términos: "...el capital se ha hecho extraterritorial, ligero, sin estorbos y desincrustado hasta un extremo sin precedentes, y el nivel de movilidad espacial que ya ha alcanzado es suficiente para chantajear a los organismos políticos vinculados con el territorio para que se sometan a sus exigencias. (...) Habiendo soltado el lastre de la maquinaria voluminosa y las enormes dotaciones de las fábricas, el capital viaja ligero, sólo con equipaje de mano: una cartera, un ordenador portátil y un teléfono celular" (Bauman, Z., La sociedad individualizada, Cátedra, Madrid, 2001, pp. 36-37).

21 Cfr. Bauman, Z., Globalizaçao. As consequências humanas, Zahar, Rio de Janeiro, 1999, pp. 19 ss. El autor cita a Paul Virilio, “Un monde superexposé: fin de l’histoire, ou fin de la géographie?”, Le Monde Diplomatique, agosto de 1997, p. 17. Matiza, sin embargo, que el origen de la tesis del fin de la geografía debe localizarse en Richard O'Brien, Global Financial Integration: The End of Geography, Chatham House/Pinter, 1992.

22 Cfr. Shawcross, W., Le Village Planétaire, Stock, Paris, 1993.

23 Cfr. Castells, M., La Era de la Información. Economía, Sociedad y Cultura, vol. 2: El Poder de la Identidad, Alianza, Madrid, 1998, p. 23.

24 Ianni, O., "A política mudou de lugar", en Dowbor, L., Ianni, O., y Resende, P.E.A. (eds.), Desafios da globalizaçao, 2ª edic, Vozes, Petrópolis, 1999, p. 17. Sobre la insuficiencia del modelo estatal y la necesidad de trascender los espacios organizativos y de cooperación, cfr., Ferrajoli, L., “Más allá de la soberanía y la ciudadanía: un constitucionalismo global”, en Carbonell, M. (comp.), Teoría de la Constitución. Ensayos escogidos, 3a edic., UNAM-Porrúa, México, 2005, pp. 397-409.

25 Capella, J.R., "Estado y Derecho ante la mundialización: aspectos y problemáticas generales", en Capella Hernández, J.R. (coord.), Transformaciones del derecho en la mundialización, CGPJ, Madrid, 2000, p. 104.

26 Capella, J.R., “Estado y Derecho ante la mundialización: aspectos y problemáticas generales”, cit., p. 106.

27 Una estimulante variante del pluralismo jurídico, en el contexto latinoamericano, nace en el seno del pensamiento crítico de aquel continente, asociado a lecturas emancipatorias, anticolonialistas y contrahegemónicas, y encuentra una vigorosa expresión en la obra de A.C. Wolkmer en Brasil y 0.Correas y J. A. de la Torre Rangel en México y D. Sánchez Rubio en España (Para una perspectiva general de esta amplia y rica corriente teórica, cfr. Wolker, A.C.; Veras Neto, F.Q. y Lixa, I.M., Pluralismo jurídico. Os novos caminhos da contemporâneidade, Saraiva, Sao Paulo, 2010.

28 Beck, U., "La reinvención de la política: hacia una teoría de la modernización reflexiva”, en Beck, U., Giddens, A. y Lash, S., Modernización reflexiva. Política, tradición y estética en el orden social moderno, Alianza, Madrid, 1997, pp. 18-20.

29 Denninger, E., "Racionalidad tecnológica, responsabilidad ética y derecho posmoderno", en Pérez Luño, A. E. (coord.), Derechos humanos y Constitucionalismo ante el tercer milenio, Marcial Pons, Madrid, 1996, pp. 64-65. La situación a la que alude Denninger es planteada también por Luis Alberto Warat al referirse a la inflación informativa de nuestro tiempo, que provoca que los grandes principios pierdan consistencia y valor: "El Derecho parece estar también afectado por la metástasís informativa de la transmodernidad. Temas que hacen a la solidaridad, a la democracia, a los Derechos Humanos, la ciudadanía, la censura, o al ejercicio de los Derechos, son alterados por una sobredosis de información que les hacen perder consistencia, casi como si no existieran" (Warat, L. A., ¿Por quién cantan las sirenas? Informe sobre eco-ciudadanía, género y derecho -incidencias del barroco en el pensamiento jurídico-, UFSC, Santa Catarina, 1996, p. 157).

30 Denninger, E., "Racionalidad tecnológica, responsabilidad ética y derecho posmoderno”,cit., p. 65. 
31 Cfr. Denninger, E.,"Racionalidad tecnológica, responsabilidad ética y derecho posmoderno, cit., pp. 61-66.

32 Evidentemente, ello conecta con: a) los planteamientos sobre la justicia distributiva global y la extensión de los derechos más allá del marco estatal para lo cual remito al trabajo de Turégano Mansilla, I., Justicia global: los límites del constitucionalismo, Palestra, Lima, 2010, que ofrece una interesante aproximación a esta problemática en conexión con el debate sobre el constitucionalismo cosmopolita. En una línea complementaria, Barranco Avilés se introduce en la fundamentación de una teoría de la justicia basada en la igual dignidad de los seres humanos en el marco del constitucionalismo contemporáneo: Cfr. Barranco Avilés, Mạ.C., "Constitución, Derechos Humanos y Filosofía del Derecho: una teoría de la justicia para el constitucionalismo contemporáneo", Anuario de Filosofía del Derecho, 2012, pp. 13-31; b) la concepción cooperativa de los derechos como razones para la acción internacional, que sitúa a los individuos como miembros de la comunidad internacional y que recaba una gobernanza cooperativa entre instituciones a nivel local, regional y mundial. Para una aproximación muy atinada y completa a estas concepciones teóricas, cfr. Iglesias Vila, M., "¿Los derechos humanos como derechos especiales? Algunas ventajas de una concepción cooperativa de los derechos humanos", Anuario de Filosofía del Derecho, 2016, pp.119-144.

33 Beck, U., ¿Qué es la globalización? Falacias del globalismo, respuestas a la globalización, Paidós, Barcelona, 1998, pp. 42-43.

34 Cfr. de Julios-Campuzano, A., En las encrucijadas de la modernidad. Política, Derecho y Justicia, Universidad de Sevilla, Sevilla, 2000, p. 299. En esta línea, resulta esclarecedor el trabajo de Bolzán de Morais, J.L., As crises do Estado e da Constituiçao e a transformaçao espaço-temporal dos Direitos humanos, $2^{\mathrm{a}}$ edic. revisada y ampliada, Livraria do Advogado, Porto Alegre, 2011.

35 Streck, L., "Las transformaciones del derecho: clasicismo y contemporaneidad", Anuario de Filosofia del Derecho, 2016, p.50.

36 Sobre esta cuestión han insistido con agudeza, entre otros, Bolzán de Morais, J.L., As crises do Estado e da Constituiçao e a transformaçao espaço-temporal dos Direitos humanos, cit. y Ferrajoli, L., Poderes salvajes. La crisis de la democracia constitucional, Trotta, Madrid, 2011.

37 Mercado, P., "Derechos insostenibles", en Estévez Araújo, J.A. (ed.), El libro de los deberes. Las debilidades e insuficiencias de la estrategia de los derechos, Trotta, Madrid, 2013, pp. 139-166; cfr. también, del mismo autor, "Libertades económicas y derechos fundamentales. La libertad de empresa en el ordenamiento multinivel europeo", Cuadernos Electrónicos de Filosofía del Derecho, 26, 2012. Disponible en. https://ojs.uv.es/index.php/CEFD/article/view/1990/3046 . Acceso: 3.10.2016, en el que el autor reflexiona sobre la primacía de los derechos de contenido económico sobre otros derechos y cómo esa primacía supone en realidad una merma en la satisfacción de los derechos sociales y de los mecanismos de justicia sustantiva del Estado de bienestar.

38 Cfr. de Julios-Campuzano, A., En las encrucijadas de la modernidad. Política, Derecho y Justicia, cit., p. 300.

39 Cfr. Denninger, E., "Racionalidad tecnológica, responsabilidad ética y derecho posmoderno", cit., pp. 53-70.

40 Sobre esta cuestión cfr. Beck, U., La sociedad del riesgo: hacia una nueva modernidad, Paidós, Barcelona, 1998. Del mismo autor, ¿Qué es la globalización? Falacias del globalismo, respuestas a la globalización, cit., pp. 65-71; Giddens, A., Un mundo desbocado. Los efectos de la globalización en nuestras vidas, Taurus, Madrid, 2000, pp. 33-48.

41 cfr. Beck, U., ¿Qué es la globalización? Falacias del globalismo, respuestas a la globalización, cit., p. 70.

42 Cfr. Brown Weiss, E., Un Mundo Justo para las Futuras Generaciones. Derecho Internacional, Patrimonio Común y Equidad Intergeneracional, Mundi-Prensa, Madrid, 1999, pp. 36-41 y 69.

43 Para una aproximación al concepto de justicia intergeneracional a partir de la idea de reciprocidad indirecta y su proyección en las relaciones entre generaciones, cfr. Lema Añón, C., "La reciprocidad indirecta y las generaciones futuras", Anuario de Filosofía del Derecho, 
44 Caso relativo a la Delimitación Marítima en el área entre Groenlandia y Jan Mayen (Dinamarca c/ Noruega), 1993, C.I.J. 38 (cit. en Brown Weiss, E., Un Mundo Justo para las Futuras Generaciones. Derecho Internacional, Patrimonio Común y Equidad Intergeneracional, cit., p. 28).

45 Caso de las Pruebas Nucleares de 1995, Nueva Zelanda c/ Francia, 1995, C.I.J., 288; cit. en Brown Weiss, E., Un Mundo Justo para las Futuras Generaciones. Derecho Internacional, Patrimonio Común y Equidad Intergeneracional, cit., pp. 28-29.

46 Opinión Consultiva sobre la legalidad de la amenaza o uso de las armas nucleares, C.I.J., 1996, cit. por Brown Weiss, E., Un Mundo Justo para las Futuras Generaciones. Derecho Internacional, Patrimonio Común y Equidad Intergeneracional, cit., p. 29.

47 Responsability and Liability under International Law for Environmental Damage, Institut de Droit International, 4 de septiembre de 1997 (cit. por Brown Weiss, E., Un Mundo Justo para las Futuras Generaciones. Derecho Internacional, Patrimonio Común y Equidad Intergeneracional, cit., pp. 28-29).

48 Serrano Moreno, J.L., Ecología y Derecho: Principios de Derecho Ambiental y Ecología Jurídica, Comares, Granada, 1992. La cita procede de la p. 15. (cfr. especialmente, pp. 55-60).

49 Cfr. de Julios-Campuzano, A., En las encrucijadas de la modernidad. Política, Derecho y Justicia, cit., ibidem.

50 Ferrajoli, L., Por uma teoria dos direitos e dos bems fundamentais, cit., p.15. En este sentido, el jurista italiano agrega que esa diferenciación tiene su origen en la diversa ascendencia teórica de las dos categorías de derechos: mientras los derechos fundamentales remiten a la filosofía iusnaturalista y contractualista de los siglos XVII y XVIII, los derechos patrimoniales se remontan a la tradición a la tradición civilista y romanista.

51 Cfr. Serrano Moreno, J.L., Ecología y Derecho: Principios de Derecho Ambiental y Ecología Jurídica, cit., p. 115.

52 Ferrajoli, L., Por uma teoria dos direitos e dos bems fundamentais, cit., pp. 70-73. Resultan muy sugerentes en este sentido, las admoniciones del profesor Pérez Luño sobre el optimismo desmedido en la incorporación de garantías ambientales en los textos constitucionales. El constitucionalismo ambiental y el derecho ecológico pueden resultar, a la postre, un espejismo, al inducir una confusión entre la realidad y el deseo (Pérez Luño, A.E., Perspetivas e tendências atuais do Estado Constitucional, Porto Alegre, 2012, pp.57-62).

53 Sobre el imapcto de las nuevas teconologías de la comunicación y de la información pueden tener sobre los derechos humanos en la era de la globalización, Cfr. mi trabajo "La ética global de los derechos humanos. Una aproximación prospectiva al impacto de las nuevas tecnologías", Cuadernos Electrónicos de Filosofía del Derecho, 22, 2011. Disponible en: https://ojs.uv.es/ index.php/CEFD/article/view/320. Acceso 02.09.2016.

54 Cfr. Carrillo-Salcedo, J.A., "El problema de la universalidad de los derechos humanos en un mundo único y diverso", en Rodríguez Palop, Mạ.E. y Tornos, A. (eds.), Derechos culturales y derechos humanos de los inmigrantes, Universidad Pontificia de Comillas, Madrid, 2000, pp. 41 ss.

55 Pureza, J.M., “¿Derecho cosmopolita o uniformador? Derechos humanos, Estado de Derecho y Democracia en la posguerra fría", en Pérez Luño, A.E. (ed.), Derechos humanos y constitucionalismo ante el tercer milenio, cit., p. 123.

\section{Alfonso de Julios-Campuzano}

Catedrático de Filosofía del Derecho

Universidad de Sevilla 